\title{
Use of the frozen elephant trunk technique for type B aortic dissection and aberrant right subclavian artery: an anatomic repair of the "arteria lusoria"
}

\author{
Giacomo Murana, Luca Di Marco, Ciro Amodio, Antonino Costantino, Roberto Di Bartolomeo, \\ Alessandro Leone, Davide Pacini \\ Cardiac Surgery Unit, Cardio-Thoracic-Vascular Department, S. Orsola Hospital, University of Bologna, Bologna, Italy \\ Correspondence to: Giacomo Murana, MD, PhD. Cardiac Surgery Unit, Cardio-Thoracic-Vascular Department, S.Orsola Hospital, University of \\ Bologna, Via Massarenti 9, 40138 Bologna, Italy. Email: g.murana@hotmail.com.
}

Submitted Jan 21, 2020. Accepted for publication Mar 12, 2020.

doi: $10.21037 /$ acs.2020.03.15

View this article at: http://dx.doi.org/10.21037/acs.2020.03.15

\section{Introduction}

Retrograde extension into the aortic arch occurs in $16.5 \%$ of patients with type B aortic dissection (TBAD) (1). This cohort of patients may be eligible for a radical repair using the frozen elephant trunk (FET) technique. The combination of surgical replacement of the aortic arch and deployment of the stent graft allows complete exclusion of the false lumen in aortic dissections. In the case of aneurysm or residual dissection, patients undergoing FET are ready for subsequent endovascular or surgical treatment (2).

The arteria lusoria represents an anatomic entity known for several years, but with little literature and few reports on its clinical relevance. Most describe the relationship between the abnormal vessel and the gastrointestinal tract, with symptoms related to the consequential esophageal compression (3). In 1994, Kieffer and colleagues proposed a classification system based on the clinical manifestations of an aberrant subclavian artery (4).

\section{Clinical vignette}

A 55-year-old woman was admitted to our hospital emergency department for sudden upper back pain in the setting of a hypertensive crisis. She described her pain as tearing, radiating to the chest and accompanied by profuse sweating. A thoracic CT scan demonstrated a TBAD with primary entry tear opposite the left subclavian artery (LSA) ostium. The dissection extended downstream to the common iliac arteries bilaterally and cranially to the middle aortic arch with bilateral common carotid artery involvement. Aortic diameter was normal, with maximum extension of $39 \mathrm{~mm}$ at the isthmus level. CT scan also showed an aberrant right subclavian artery (RSA), arising distal to the LSA ostium. Both subclavian arteries were affected by the dissection.

The patient was then admitted in our cardiac surgery department with the diagnosis of uncomplicated acute TBAD. Since malperfusion syndrome or impending rupture were not present, medical therapy was initiated with intravenous infusion of nitroprusside and metoprolol to control chest pain and blood pressure. Two days later, a new CT angiogram was performed for the recurrence of chest pain. Neither changes in the aortic features nor malperfusion were found.

After evaluation by the aortic team, given the arch anatomy and absence of a valid landing zone for endovascular repair, the patient was scheduled for a radical surgical approach through the FET technique.

\section{Surgical technique}

\section{Preparation and exposition}

The surgical approach includes full median sternotomy. The supra-aortic vessels were visualized and isolated by cranial dislocation of the anonymous venous trunk by means of two stay stitches. Central cannulation was chosen for cardiopulmonary bypass (CPB), and the arterial cannulation site was the ascending aorta. Venous drainage was achieved 
by cannulation of the right atrium. A left ventricular drain was inserted through the right superior pulmonary vein. During cooling time, the aberrant RSA was found in the right supraclavicular region and an $8 \mathrm{~mm}$ dacron tube was anastomosed termino-terminally and left free for later reattachment on the arch prosthesis.

\section{Operation}

Circulatory arrest was performed at a target nasopharyngeal temperature of $25^{\circ} \mathrm{C}$. Myocardial protection was achieved with infusion of cold crystalloid cardioplegia. After the arch was partially resected, the cannulation of supraaortic vessels was realized for antegrade cerebral perfusion. Ishimaru zone 2 aortic arch was prepared using an external Teflon felt and closing the LSA ostium. A 22/24 mm Thoraflex Hybrid graft was deployed into the descending aorta with coverage of the aberrant subclavian ostium. The distal stump was secured with a running suture to exclude further distal dissection. Systemic perfusion was reestablished via the graft side-branch. Before re-implanting the supra-aortic vessels, the prosthetic tube for the RSA was anastomosed termino-laterally to the first branch of the Thoraflex prosthesis; a new innominate artery was created and the supra-aortic vessels re-implantation was completed in an anatomic way: firstly the right common carotid, then left common carotid artery and finally, the LSA. At the end of the procedure, proximal anastomosis was performed between the ascending aorta and the vascular prosthesis, reinforcing the suture with Teflon felt.

Subsequently, CPB was weaned with no need for ionotropic support. Operative times were as follows: $\mathrm{CPB}$ time: 215 minutes; myocardial ischemic time: 98 minutes and ASCP time: 95 minutes.

\section{Post-operative outcome}

The post-operative period was characterized by respiratory failure requiring prolonged orotracheal intubation and slow weaning from invasive mechanical ventilation. Postoperative CT scan showed a good result of the procedure.

\section{Comments}

The FET technique has continued to gain popularity in recent years. This may be attributed to the facilitated approach to the distal anastomosis by performing it in a more proximal level of the aortic arch, generally zone 2 (2). This technical advantage allows better control of hemostasis and significant reduction in risk of paraplegia by an early visceral reperfusion and proximalization of the stent graft landing zone. Moderate systemic hypothermia and bilateral antegrade selective cerebral perfusion (ASCP) are the cornerstones of FET technique in our center (5). In cases of aortic pathology associated with the presence of aberrant RSA, some authors suggest an extra-anatomic bypass for vessel re-implantation (3). In this specific case, we were able to perform direct anastomosis of the arteria lusoria on the Thoraflex graft. Through accurate study of the pre-operative CT angiogram, we saw that the anomalous vessel had a retro-esophageal course and did not provide significant side branches. We decided to isolate the RSA by extending the sternotomy incision of $5 \mathrm{~cm}$ into the right supraclavicular region. An $8 \mathrm{~mm}$ vascular graft was then interposed between the vessel and the first branch of the Thoraflex to create a new prosthetic brachiocephalic trunk. Other options could involve the graft for the lusoria placed directly into the ascending prosthesis tract or joined to the lateral branch of the Thoraflex, which we usually utilize for visceral reperfusion. However, these two hypothetical options would have created a longer prosthetic graft, with increased risk of reduced patency in the longterm. Despite the FET technique being simplified over the years, cases like this confirm the wide versatility of the graft but reinforce that surgical expertise is essential as well as accurate pre-operative planning. This case represents a possible solution to achieve fully anatomical re-implantation of the supra-aortic vessels in aortic arch reconstruction.

\section{Acknowledgments}

None.

\section{Footnote}

Conflicts of Interest: The authors have no conflicts of interest to declare.

Open Access Statement: This is an Open Access article distributed in accordance with the Creative Commons Attribution-NonCommercial-NoDerivs 4.0 International License (CC BY-NC-ND 4.0), which permits the noncommercial replication and distribution of the article with the strict proviso that no changes or edits are made and the original work is properly cited (including links to both the formal publication through the relevant DOI and the license). 
See: https://creativecommons.org/licenses/by-nc-nd/4.0/.

\section{References}

1. Nauta FJ, Tolenaar JL, Patel HJ, et al. Impact of Retrograde Arch Extension in Acute Type B Aortic Dissection on Management and Outcomes. Ann Thorac Surg 2016;102:2036-43.

2. Czerny M, Schmidli J, Adler S, et al. Current options and recommendations for the treatment of thoracic aortic pathologies involving the aortic arch: an expert consensus document of the European Association for Cardio-

Cite this article as: Murana G, Di Marco L, Amodio C, Costantino A, Di Bartolomeo R, Leone A, Pacini D. Use of the frozen elephant trunk technique for type B aortic dissection and aberrant right subclavian artery: an anatomic repair of the "arteria lusoria". Ann Cardiothorac Surg 2020;9(3):254-256. doi: $10.21037 /$ acs. 2020.03 .15
Thoracic surgery (EACTS) and the European Society for Vascular Surgery (ESVS). Eur J Cardiothorac Surg 2019;55:133-62.

3. Jahangeer S, Bashir M, Harky A et al. Aberrant subclavian: new face of an old disease. J Vis Surg 2018;4:108.

4. Kieffer E, Bahnini A, Koskas F. Aberrant subclavian artery: surgical treatment in thirty-three adult patients. J Vasc Surg 1994;19:100-9.

5. Di Marco L, Leone A, Murana G, et al. Acute type A aortic dissection: Rationale and outcomes of extensive repair of the arch and distal aorta. Int J Cardiol 2018;267:145-9. 